\title{
Fatty acids Compositions in Male's Gonads of the Red Sea fish Rhabdosargus sarba during the spawning season
}

\author{
Suhaila A. Qari", Samia G. Moharram, Safaa A. Alowaidi \\ Department of Biological Sciences. Faculty of Science. King Abdulaziz University, Jeddah, Saudi Arabia \\ Email address: \\ sqari@kau.edu.sa (Suhaila A. Qari)
}

To cite this article:

Suhaila A. Qari, Samia G. Moharram, Safaa A. Alowaidi. Fatty acids Compositions in Male's Gonads of the Red Sea Fish Rhabdosargus sarba During the Spawning Season. American Journal of Life Sciences. Vol. 2, No. 2, 2014, pp. 103-107. doi: 10.11648/j.ajls.20140202.21

\begin{abstract}
A total of 27 fatty acids (FAs) were identified in testis throughout the spawning season of male $R$. sarba. In male gonad saturated fatty acids (SFA) were the main fatty acid group in total lipid in testis (34\%) followed by PUFA (29.1\%) and MUFA (11.6\%). In all maturation stages SFA were the main fatty acid group in testis (30.4-35.4\%). Of individual fatty acid, the major constituents of SFA were Palmitic acid C16:0 (18. 5\%) and Stearic acid C18:0 (8.5\%) in nearly ripe and ripe stages respectively. Oleic acid C18:1 (8.8\%) was found to be the main MUFA in ripe stage and Linoleic acid C18:2 (10.8\%) was the main PUFA in nearly ripe stage. During spawning and maturation stages there were a significant differences in total SFA and MUFA $(\mathrm{P}<0.05)$.
\end{abstract}

Keywords: Sparidae, Rhabdosargus sarba, Fish, Fatty Acids, Spawning, Gonads, Red Sea

\section{Introduction}

Fish lipids are generally characterized by possessing large amounts of saturated and unsaturated fatty acids mostly associated with triacylglycerols and minor amounts of phospholipids [1]. Fatty acids (FA) and particularly polyunsaturated fatty acids (PUFA) are functionally essential for normal growth, development and reproduction in fish [2]. Lipids and specifically fatty acids are the preferred source of metabolic energy for growth , reproduction and swimming in fish especially marine fish as evidenced by the very high oil levels (more than $20 \%$ of the wet weight) [3]. Recent studies have clearly shown the importance of polyunsaturated fatty acids (PUFAs) nutritional values for human health [4]. The nutritional importance of fish consumption is in great extent associated with the content of polyunsaturated fatty acids especially omega- 3 fatty acids ( $\omega-3$ FAs) and omega- 6 fatty acids $(\omega-$ 6FAs) [5]. The aim of the study to examine the fatty acid profiles in the male of $R$. sarba from the Red Sea. It is emphasized that no earlier studies of the fatty acids composition of this species occur.

\section{Materials \& Methods}

\subsection{Fish Samples}

Fish samples were obtained monthly from Bangalah market fish in Jeddah, Red Sea from December to March 2011. Fishes were transported to the laboratory in ice aquarium and then the total length, standard length and weight were measured. Fishes were dissected; testes were removed, weighed and thoroughly examined to determine the maturity stag and the gonad index (testis weight / total fish body weight $\times 100$ ) was calculated. On the basis of collected commercial data and using the maturity scale described by West (1990) we estimated that the spawning fish samples were in the categories III-VI which characterizes $R$. sarba of mature, ripe and spawning condition.

\subsection{Lipid Extraction}

$10 \mathrm{ml}$ of concentrated hydrochloric acid were added to $10 \mathrm{~g}$ of the sample in a conical flask and immersed in boiling water until the sample was dissolved. At this stage the mixture changed to brown or violet in colour and the fat was seen to collect on the surface. The conical was cooled and the fat was extracted by shaking with $30 \mathrm{ml}$ of diethyl ether. The extract was bowled after allowing the layers to separate into a weighed flask. The extraction was repeated three times more and distilled off the solvent then the fat dried at $100^{\circ} \mathrm{C}$, cooled and weighed. 


\subsection{Methylation of Lipid}

$50 \mathrm{mg}$ of lipid was put in a tube , $5 \mathrm{ml}$ of methanolic sulphuric acid $(1 \mathrm{ml}$ conc sulphuric acid and $100 \mathrm{ml}$ methanol) was added and $2 \mathrm{ml}$ of benzene, the tube well closed and placed in water bath at $90 \mathrm{oC}$ for an hour and half. After cooling, $8 \mathrm{ml}$ water and $5 \mathrm{ml}$ petroleum was added shacked strongly and the ethereal layer was separated in a dry tube, evaporated to dryness.

\subsection{Gas Chromatographic (GC) Conditions}

The fatty acid methyl esters were analyzed using a Hewlett Packard (HP 6890) chromatography, asplit /splitless injector and flame ionization detector (FID).

Data were analysed using an independent Student t-test and one way ANOVA for significant differences. The level of significance used was $\mathrm{P}<0.05$.

\section{Results}

The fatty acid compositions from testis are presented in Table ( $1 \& 2$ ), 27 fatty acids were identified, ranged from C6:0 to C22:6. On average, 34\% saturates, $29 \%$ polyunsaturates and $12 \%$ monounsaturates, approximately were found in the testis of spawning R. sarba (Table1).

Table 1. Saturated (SFA), Monounsaturated (MUFA) and Polyunsaturated (PUFA) Fatty acids compositions of R. sarba.

\begin{tabular}{|c|c|}
\hline SFA & Male \\
\hline C6:0 & $0.680 \pm 0.365$ \\
\hline $\mathrm{C} 8: 0$ & $1.387 \pm 0.255$ \\
\hline $\mathrm{C} 10: 0$ & $0.173 \pm 0.172$ \\
\hline C11:0 & $0.4729 \pm 0$ \\
\hline C12:0 & $0.137 \pm 0.038$ \\
\hline C13:0 & $2.608 \pm 0.923$ \\
\hline C14:0 & $1.506 \pm 0.512$ \\
\hline C15:0 & $1.505 \pm 0.552$ \\
\hline $\mathrm{C} 16: 0$ & $16.35 \pm 2.1208$ \\
\hline C17:0 & $1.152 \pm 0.4546$ \\
\hline C 18:0 & $7.520 \pm 1.258$ \\
\hline $\mathrm{C} 20: 0$ & $0.391 \pm 0.340$ \\
\hline \multicolumn{2}{|l|}{$\mathrm{C} 21: 0$} \\
\hline \multicolumn{2}{|l|}{ C23:0 } \\
\hline \multicolumn{2}{|l|}{$\mathrm{C} 24: 0$} \\
\hline Total saturates & $33.88762 *$ \\
\hline \multicolumn{2}{|l|}{ MUFA } \\
\hline $\mathrm{C} 14: 1$ & $1.3919 \pm 0.429$ \\
\hline C15:1 & $0.5736 \pm 0.135$ \\
\hline C16:1 & $2.764 \pm 0.471$ \\
\hline $\mathrm{C} 17: 1$ & $0.491 \pm 0.282$ \\
\hline C18:1 & $5.339 \pm 2.996$ \\
\hline $\mathrm{C} 20: 1$ & $0.446 \pm 0.126$ \\
\hline $\mathrm{C} 22: 1$ & $0.6317 \pm 0$ \\
\hline Total monoenes & 11.63913 \\
\hline \multicolumn{2}{|l|}{ PUFA } \\
\hline C18:3 & $0.360 \pm 0.258$ \\
\hline C18:2 & $9.467 \pm 0.971$ \\
\hline C20:5 & $3.479 \pm 1.049$ \\
\hline $\mathrm{C} 20: 4$ & $3.384 \pm 1.582$ \\
\hline $\mathrm{C} 20: 3$ & $0.344 \pm 0$ \\
\hline $\mathrm{C} 20: 2$ & $1.234 \pm 0.7439$ \\
\hline $\mathrm{C} 22: 2$ & $6.925 \pm 0.494$ \\
\hline $\mathrm{C} 22: 6$ & $3.882 \pm 2.1570$ \\
\hline Total polyenes & 29.07818 \\
\hline
\end{tabular}

(*Values are significantly different $(\mathrm{P}<0.05))$

\subsection{Saturated Fatty Acids (SFA)}

It is obvious that the dominant fatty acids among SFA in males was Palmitic acid (C16:0, 16.4\%) followed by Stearic acid (C 18:0, $7.5 \%$ ). The most abundant SFA in herring was Palmitic acid C16:0 (ranging from 13.5 to $18.5 \%$ in different maturity stages). The relatively high amount of $\mathrm{C} 16: 0$ present in the nearly ripe stage. However, a decreasing trend in the amount of C16:0 in the testis was noticed during spawning stage (Table2).

Table 2. Fatty acid composition in $R$. sarba testes, during them spawning season (2010-2011).

\begin{tabular}{ccccc}
\hline & \multicolumn{4}{c}{ Stages } \\
Lipid parameter & $\begin{array}{c}\text { Nearly ripe } \\
\text { December }\end{array}$ & $\begin{array}{c}\text { Ripe } \\
\text { January }\end{array}$ & $\begin{array}{c}\text { Spawning } \\
\text { February }\end{array}$ & $\begin{array}{c}\text { Spawning } \\
\text { March }\end{array}$ \\
\hline Total lipid & 0.19 & 0.1 & 0.1 & 0.43 \\
SFA & & & & \\
C6:0 & 0.890 & 1.0662 & 0.257 & 0.507 \\
C8:0 & 1.2307 & 1.7327 & 1.1621 & 1.424 \\
C10:0 & 0.0849 & 0.4279 & 0.1244 & 0.055 \\
C11:0 & & & & 0.4729 \\
C12:0 & 0.1168 & 0.126 & 0.195 & 0.1132 \\
C13:0 & 1.913 & 2.217 & 3.967 & 2.336 \\
C14:0 & 1.206 & 1.1257 & 2.247 & 1.446 \\
C15:0 & 1.1005 & 1.167 & 2.301 & 1.4516 \\
C16:0 & 18.4915 & 17.3157 & 13.541 & 16.051 \\
C17:0 & 1.6427 & 1.4320 & 0.717 & 0.8167 \\
C 18:0 & 8.5026 & 7.279 & 5.835 & 8.4645 \\
C20:0 & 0.24009 & 0.781 & & 0.1540 \\
Total & $35.419 *$ & 34.672 & 30.350 & 33.296 \\
MUFA & & & & \\
C14:1 & 1.083 & 1.2019 & 2.027 & 1.255 \\
C15:1 & 0.520 & 0.5486 & 0.768 & 0.457 \\
C16:1 & 3.185 & 3.1594 & 2.380 & 2.332 \\
C17:1 & 0.2516 & 0.242 & 0.731 & 0.739 \\
C18:1 & 3.424 & 3.800 & & 8.792 \\
C20:1 & 0.357 & & & 0.536 \\
C22:1 & 0.6317 & & & \\
Total & 9.4552 & 8.952 & 5.907 & 14.113 \\
PUFA & & & & \\
C18:3 & 0.6149 & 0.551 & 0.1406 & 0.135 \\
C18:2 & 10.841 & 8.629 & 9.419 & 8.978 \\
C20:5 & 2.8155 & 4.530 & 2.369 & 4.2037 \\
C20:4 & 1.788 & 4.604 & 2.266 & 4.876 \\
C20:3 & 0.3446 & & & \\
C20:2 & 2.0917 & & 0.763 & 0.846 \\
C22:2 & 7.221 & 6.863 & 6.253 & 7.363 \\
C22:6 & 2.967 & 2.863 & 7.1089 & 2.589 \\
Total & 28.686 & 28.0416 & 28.322 & 28.994 \\
\hline & & & &
\end{tabular}

(* Values are significantly different $(\mathrm{P}<0.05)$

\subsection{Monounsaturated Fatty Acids (MUFA)}

Monounsaturated fatty acids constituted nearly $16 \%$ of the total fatty acids in testis of $R$. sarba (Table1). The major MUFA were Oleic acid (C18:1, 5.3\%) and Palmitoleic acid (C16:1, 2.8\%). MUFA dominated in spawning stage due to the abundance of Oleic acid C18:1 which occurred at more than $30 \%$ in this stage. The proportion of $\mathrm{C} 18: 1$ was threetimes higher in the spawning stage $(8.8 \%)$ and about 2.5 times greater compared to those from nearly and ripe stages (Table2). 


\subsection{Polyunsaturated Fatty Acids (PUFA)}

Among PUFAs, Linoleic (C18:2, 9.5\%), and (C22:2, 7\%) were the major acids. The testis of $R$. sarba had similar PUFA proportions $(28 \%)$ in the four maturity stages (Table2). The Linoleic acid C18:2 is dominant PUFAs in all maturity stages, the highest proportion of $\mathrm{C} 18: 2$ occurred in the nearly ripe stage $(11 \%)$ while the ripe stage contained a relatively lower proportion (9\%). Moreover, a relatively higher PUFAs of Docosadienoic acid C22:2 occurred in all maturity stages with an average of 7\% (Table2). Highly unsaturated fatty acids (HUFA) namely EPA and DHA are not dominant PUFAs in the testis of $R$. sarba. DHA occurred in greater proportion than EPA in spawning stage spawning $(7 \%)$ while the other three stages contained a similar proportion (Table2). There were a significant differences $(\mathrm{P}<0.05)$ in total SFA and MUFA during spawning season.

Table 2 represents fatty acid (FA) profile of testis samples obtained in the spawning season (December, January, February and March.). No significant variations were indentified in the total saturated fatty acid ( $\sum$ SFA), monounsaturated fatty acid( $\sum$ MUFA) and polyunsaturated fatty acid ( $\sum$ PUFA) amongst months and the highest values were $35.41 \%$ (in nearly ripe stage), $14.11 \%$ and $29 \%$ (lat spawning) respectively. During the spawning season (December-March) the highest value for $\sum$ SFA was observed in nearly ripe stage (December) as $35.41 \%$ $(\mathrm{P}>0.05)$. Palmitic acid (C16:0) and Stearic acid (C18:0) were the major constituents of the total saturated fatty acids. Variations amongst months were also observed for $\sum$ MUFA ranging from $5.9 \%$ to $14.11 \%$. Their concentration decreased in both ripe and spawning stage reaching to the lowest value (5.9\%) in spawning stage. Oleic acid (C18:1) was found to be the main MUFA varying between $3.4 \%$ and $8.8 \%$ with the highest value at the end of spawning period (March) followed by Palmitoleic acid (C16:1) where both nearly ripe and ripe stages constituted the highest level $(3.2 \%)$, whereas the other MUFAs were noticed to be in negligible amount. Significant variations were indentified between total saturated fatty acid and monounsaturated fatty acid among months. Fluctuation in $\sum$ PUFA, the testes samples were observed to be constant about $28 \%$. It is clear that Linoleic acid C18:2 was the main PUFA and its level decreased from $10.8 \%$ in nearly ripe stage to $8.6 \%$ in ripe stage. Docosadienoic C22:2 is found to be the second major PUFA, spawning and nearly ripe testis had the highest level among months $(7.4 \%, 7.2 \%)$ respectively.

\section{Discussion}

There is number of classifications available by which fish is divided into groups, according to their lipid content. The species $R$. sarba belong to the group of high proteinlow fat category. Saturated fatty acids (SFA) of total lipid constituted the majority of the fatty acids pool followed by polyunsaturated fatty acids (PUFA) and monounsaturated fatty acid (MUFA) in males of $R$. sarba. The results are in agreement with those reported by [6-8] for sea bass (D. labrax).

The major fatty acids in male of $R$. sarba were Palmatic acid (C16:0), Stearic acid (C18:0), Oleic acid (C18:1), Linoleic acid (C18:2), Eicosapentaenoic acid, (EPA, C20:5), Arachidonic acid (AA, 20:4), C22:2 and Docosahexaenoic acid (DHA, C22:6). This result is similar to those reported for some selected Indian Fishes [9]. Grigorakis et al. [10] also determined that these fatty acids constituted the basic components of fatty acids of gilthead sea bream (S. aurata). Similarly, Varljen et al. [11] found that these fatty acids were the basic fatty acids of Diplodus vulgaris. Also, the same results were recorded for $S$. aurata and D. sargus by Özyurt et al. [12]. The C16:0 and C18:1 fatty acids were mainly catabolic for energetic purposes [13]. High amounts of all these acids were consumed during fish growth and development and they were easily catabolic by the mitochondria [14].

The saturated fraction constituted in male $33.88 \%$ of the total fatty acids, Palmitic acid C16:0 is the most important fatty acid followed by Stearic acid C18:0. The dominance of Palmitic acid in fish lipid has been reported by other authors [15-18]. In the present study the Palmitic acid showed higher level in testes which is noticed for being a predominant source of potential metabolic energy in fish during growth [19]. Similar result has been reported previously in the roe of herring [20]. Also, this may be indicator for male need more supplying of energy requirements for changing the sexes in $R$. sarba from male to female (hermaphrodite ) .

As far as for MUFA fraction Oleic acid (C18:1) was the basic fatty acid. Similar results were reported for gilthead sea bream by Grigorakis et al. [10], and for sea bass by Bhouri et al., [21]. In the present study Linoleic acids (C18:2) was the prominent PUFA $(9.47 \%)$, this result is in accordance with Bayir et al. [22] who reported that C18:2 was the major PUFA for gilthead sea bream and twobanded bream (Sparidae). Similar finding have been reported in three Tunisian silverside fish [23]. Higher proportion of $\mathrm{C} 18: 2$ have been reported in Baltic herring which have been linked to dietary factors [24]. The results concerning variation in the present study generally agree with the previously reported finding for sparidae species where fatty acid compositions studied in relation to the reproductive cycles, specially reduction in PUFA including EPA and DHA [25].

Marine fish have low or no capacity to synthesize highly unsaturated fatty acids (HUFAs) from C18 fatty acids. HUFAs are important components of cell membranes and are thought to play important roles in membrane fluidity, modulation of enzyme activity, neural development and regulation of stress resistance. Especially, Eicosapentaenoic acid (EPA: 20:5n-3) and Docosahexaenoic acid (DHA: 22:6n-3) were considered as dietary essential fatty acids for normal growth and survival in most marine fish [26]. Linoleic acids (C18:2) was the prominent PUFA in males $R$. 
sarba followed by C22:2 (6.93\%), Docosahexaenoic acid (DHA) Eicosapentaenoic acid (EPA) and Arachidonic acid (AA). This result is similar to those reported for Malaysian marine fishes, Eicosapentaenoic acid (EPA) and Docasahaexaenoic acid (DHA) were found more in marine fishes PUFAs than in freshwater fishes [27].

In the present study, arachidonic acid (AA) showed lower levels (3.4\%). Marine fish species generally have only PUFA which originate from marine phytoplankton. Therefore AA levels were generally low or negligible in total fatty acids of lipid of marine fish species [28], the content of AA in marine fishes were lower than freshwater fishes . Therefore, high levels of AA may be useful as a lipid biomarker of herbivorous fishes which prefer seaweed [29].

Although C20:4 has similar biologically importance as EAP and DHA, it is often neglected in fish because it occurs only at very low concentration, despite possessing vital functions as main precursor of various Eicosanoids [3], that have important roles in a variety of physiological functions including osmoregulation, cardiovascular function and the function of reproductive systems [30]. Prostaglandins (PG) plays an important role in fish reproduction [31] with AA being the principle $\mathrm{PG}$ precursor involved in spawning activity of fishes including sperm production [32] and its lower levels probably due to its mobilization. Evidence for the importance of AA in reproduction was first identified in European sea bass brood stock [33,34].

DHA content of lipids in tropical and subtropical marine fish species were reported to be lower than those of arctic and subarctic ones [35]. Fishes living in warm-water seas do not appear to require as much DHA in their cell membranes as cold-water species [36]. The lipid content of tropical fish species is generally influenced by high ambient temperature and the membrane lipids of these fishes are easily fluidized even if the major fatty acids in their lipids are composed of saturated and monoenoic fatty acids.

Levels of C16:0 and C18:1 and low levels of HUFA were characteristic for neutral lipids of most marine fish [37]. This is also in concordance with the common opinion that fish species accumulate depot lipids composed mainly of saturated and monoene fatty acids [38].

\section{Conclusions}

From the present study it has been shown that 27 fatty acids were detected in testis of male $R$. sarba. Saturated fatty acids (SFA) were the main fatty acid group in total lipid followed by polyunsaturated fatty acids (PUFA) and monounsaturated fatty acids (MUFA). The major constituents of SFA were palmitic and stearic acids in nearly ripe and ripe stages respectively. Oleic acid was found to be the main MUFA in ripe stage and linoleic acid was the main PUFA in nearly ripe stage.

\section{Acknowledgments}

This research was supported by grants from the King Abdulaziz City for Science and Technology under grant no. (T-T-10-0179). The authors therefore acknowledge with thanks KACST financial support.

\section{References}

[1] Shahidi, F. and Wanasundara, M.N., 1998. Omeqa-3fattyaci concentrate nutritional aspect and production technologies. Trend. Food Scien. \& Technol., 9:230-240.

[2] Sargent, J.R.; Tocher, D.R. and Bell, J.G., 2002. In: J.E., Halver; R.W., Hardy (Eds.). "The lipids" Fish Nutrition.3rd edition. Academic Press, San Diego, pp. 181-257.

[3] Tocher, D.R., 2003. Metabolism and Function of Lipids and Fatty Acids in Teleost fish. Rev. Fish. Sci., 11(2): 107-184.

[4] Pirestani, S.; Sahari, M.A. and Barzegar, M., 2010. Fatty Acids Changes during Frozen Storage in Several Fish Species from South Caspian Sea. J. Agr. Sci. Tech., 12: 321329.

[5] Marichamy, G.; Raja, P.; eerasingam, S.V; Rajagopal, S. and enkatachalapathy, R.V., 2009. Fatty acids composition of Indian mackerel Rastrilliger Kanagurta under different cooking methods. Current Research. J. Bio. Sci, 1(3): 109112 .

[6] Alasalvar, C.; Taylor, K.D.A.; Zubcov, E.; Shahidi, F. and Alexis, M., 2002. Differentiation of cultured and wild sea bass (Dicentrarchus labrax) total lipid content, fatty acid and trace mineral composition. Food. Chem, 79: 145-150.

[7] Periago, M.J.; Ayala, M.D.; Lopez-Albors, O.; Abdel, I.; Martinez, C.; Garcia- Alcazar A.; et al., 2005. Muscle cellularity and flesh quality of wild and farmed sea bass, Dicentrarchus labrax L. Aquaculture, 249: 175-188.

[8] Erdem, M.E.; Baki, B. and Samsun, S., 2009. Fatty Acid and Amino Acid Compositions of Cultured and Wild Sea Bass (Dicentrarchus labrax L., 1758) from Different Regions in Turkey. J. Anim. Vet. Adv, 8 (10): 1959-1963.

[9] Jakhar, J.K.; Pal, A.K.; Devivaraprasad Reddy, A.; Sahu, N.P; Venkateshwarlu, G.; Vardia, H.K., 2012. Fatty Acids Composition of Someselected Indian Fishes. African Journal of Basic \& Applied Sciences, 4 (5): 155-160.

[10] Grigorakis, K.; Alexis, M.N.; Taylor, K.D.A. and Hole, M., 2002. Comparison of wild and cultured gilthead sea bream (Sparus aurata); composition, appearance and seasonal variation. Int. J. Food. Sci. Tech, 37: 477-484.

[11] Varljen, J.; S־uli, S.; Brmalj, J.; Batii, L.; Obersnel, V. and Kapovi, M., 2003. Lipid classes and fatty acid composition of Diplodus vulgaris and Conger conger originating from the Adriatic Sea. Food. Techno. Biotech., 41: 149-156.

[12] Özyurt, G.; Polat, A. and Ozkutuk, S., 2005. Seasonal changes in the fatty acids of gilthead sea bream (Sparus aurata) and white sea bream (Diplodus sargus) captured in Iskenderun Bay, eastern Mediterranean coast of Turkey. Europ. Food Res. \& Tech., 220(2): 120-124.

[13] Ostaszewska, T., 2005. Developmental changes of digestive system structures in pike-perch Sander lucioperca L. Elect. J. Ichth., 2: 65-78. 
[14] Henderson, R.J., 1996. Fatty acid metabolism in freshwater fish with particular reference to polyunsaturated fatty acids. Arch. Anim. Nutr, 49: 5-22.

[15] Bandarra, N.M.; Batista, I.; Nunes, M.L. and Empis, J.M., 2001. Seasonal Variation in the Chemical Composition of Horse Mackerel (Trachurus trachurus). Eur. Food Res. Technol, 212: 535-539.

[16] Osman, N.H; Suriah, A.R. and Law, E.C., 2001. Fatty acid composition and cholesterol content of selected marine fish in Malaysian waters. Food Chem., 73: 55-60.

[17] Aidos, I.; Van Der Padt, A.; Luten, J.B. and Boom, R.M., 2002. Seasonal Changes in Crude and Lipid Composition of Herring Fillets, Byproducts and Respective Produced Oils. J. Agr. Food. Chem, 16: 4589-4599.

[18] Passi, S.; Cataudella, S.; Di Marco, P.; De Simone, F. and Rastrelli, L., 2002. Fatty Acid Composition and Antioxidant Levels in Muscle Tissue of Different Mediterranean Marine Species of Fish and Shellfish. J. Agr. Food Chem., 50: 73147322.

[19] Henderson, R.J.; Sargent, J.R. and Hopkins, C.C.E., 1984. Changes in the content and fatty acid composition of lipid in an isolated population of the capelin, Mallotus villosus, during sexual maturation and spawning. Mar. Biol, 78: 255263.

[20] Huynh, M.D.; Kitts, D.D.; Hu, C. and Trites, A.W., 2007. Comparison of fatty acid profiles of spawning and nonspawning Pacific herring, Clupea harengus pallasi, Comp. Bioch. Phys, 146(B): 504-511.

[21] Bhouri, A.M.; Bouhlel, I.; Chouba, L.; Hammami, M.; ElCafsi, M. and Chaouch, A., 2010. Total lipid content, fatty acid and mineral compositions of muscles and liver in wild and farmed sea bass (Dicentrarchus labrax). Afr. J. Food Sci, 4: $522-530$.

[22] Bayır, A.; Haliloğlu, H.İ.; Sirkecioğlu, A.N. and Aras, N.M., 2006. Fatty Acid Composition in Some Selected Marine Fish Species Living in Turkish Waters. J. Scien. Food \& Agricul, 86:163-168.

[23] Bouriga, N.; Selmi, S.; Faure, E. and Trabelsi, M., 2010. Biochemical composition of three Tunisian silverside (fish) populations caught in open sea, lagoon and island coasts. Afri. J. Biotech, 9 (26): 4114- 4119.

[24] Linko, R. R.; Kaitaranta, J.K. and Vuorela, R., 1985. Comparison of the fatty acids in Baltic herring and available plankton feed. Comp. Biochem. Physiol, B 82: 699-705.

[25] Batičić, L.; Varljen, N.; Butorac, M.Z.; Kapović, M. and Varljen, J., 2009. Potential value of hepatic lipids from white sea bream (Diplodus sargus, L.) as a Good Source of Biomedical Components: Seasonal Variations. Food Technol. Biotechnol, 47(3): 260-268.

[26] Suloma, A. and Ogata, H.Y., 2011. Arachidonic acid is a
Major Component in Gonadal Fatty acids of Tropical Coral Reef fish in the Philippines and Japan. J Aquac Res Develop, 2:111. doi: 10.4172/2155-9546.1000111.

[27] Mohamad, N.A.; Mohamad, J., 2012. Fatty Acids Composition of Selected Malaysian Fishes. Sains Malaysiana, 41(1): 81-94.

[28] Saito, H.; Yamashiro, R.; Alasalvar, C. and Konno, T., 1999. Influence of Diet on Fatty Acids of Three Subtropical Fish, Subfamily Caesioninae (Caesio diagramma and C. tile) and Family Siganidae (Siganus canaliculatus). Lipids, 34 (10): 1073-82.

[29] Sargent, J. R.; Parkes, R.J.; Mueller-Harvey, I.; and Henderson, R.J., 1988. Lipid Biomarkers in Marine Ecology, in Microbes in the Sea (Sleigh, M.A., ed.), pp. 119-138, Ellis Horwood Ltd., Chichester.

[30] Cejas, J.R.; Almansa, E.; Jerez, S.; Bolanos, A.; Smaper, M. and Lorenzo, A., 2004. Lipid and fatty acid composition of muscle and liver from wild and captive mature female broodstocks of white seabream, Diplomdus sargus. Comp. Biochem. Physiol, B138: 91-102.

[31] Stacey, N.E. and Goetz, F.W., 1982. Role of Prostaglandins in fish reproduction. Can. J. Aquat. Sci., 39: 92-98.

[32] Wathes, D.C.; Abayasekara, D.R.E. and Aitken, R.J., 2007. Polyunsaturated fatty acids in male and female reproduction. Biol. Reprod., 77:190-201.

[33] Thrush, M.; Navas, J.M.; Ramos, J.; Bromage, N., Carrillo, M. and Zanuy, S., 1993. The effect of artificial diets on lipid class and total fatty acid composition of cultured sea bass (Dicentrarchus labrax). Actas IV Congr. Nac. Acuicult., 2124 Sept. 1993, Ila de Arousa, Spain, 37- 42.

[34] Navas, J.M.; Bruce, M.; Thrush, M.; Farndale, B.M.; Bromage, N.; Zanuy, S.; Carrillo, R.; Bell, J.G. and Ramos, J., 1997. The impact of seasonal alteration in the lipid composition of broodstock diets on egg quality in the European sea bass. J. Fish Biol., 51: 760-773.

[35] Phleger, C.F.; and Laub, R.J., 1989. Skeletal Fatty Acids in Fish from Different Depths Off Jamaica. Comp. Biochem. Physiol., 94B: 329-334.

[36] Fodor, E.; Jones, R.H.; Kitajika, K.; Dey, I. and Farkas, T., 1995. Molecular Architecture and Biophysical Properties of Phospholipids During Thermal Adaptation in Fish: An Experimental and Model Study. Lipids, 30: 1119-1126.

[37] Sargent, J. R.; Henderson, R.J. and Tocher, D.R., 1989. The lipids. In Fish Nutrition (Halver, J., ed.), pp. 153-218. New York: Academic Press.

[38] Kozlova, T.A. and Klotimchenko, S.V., 2000. Lipids and fatty acids of two pelagic cottoid fishes (Comephorus spp) endemic to lake Baikal. Comp. Biochem. Hysiol, B 126: $477-485$. 